\title{
Gasification of char particles in packed beds: analysis and results
}

\author{
S. Dasappa ${ }^{1, *}$ and P. J. Paul ${ }^{2}$ \\ ${ }^{1}$ ASTRA, Indian Institute of Science, Bangalore 560 012, India \\ ${ }^{2}$ Department of Aerospace Engineering, Indian Institute of Science, Bangalore 560 012, India
}

\begin{abstract}
SUMMARY
In this paper a packed bed of char particles is considered for experimental study and analysis. The packed char bed is modelled by extending the single-particle analysis (Dasappa et al., 1994a, Chem. Eng. Sci. 49-2: 223-232. Dasappa et al., 1994b, Twenty-fifth Symposium (International) on Combustion, pp. 1619-1628. Dasappa et al., 1998, Twenty-seventh Symposium (International) on Combustion, pp. 1335-1342.). All the reactions related to gasification are introduced into the reaction system as in Dasappa et al. (1998). The propagation of the reaction front into the packed char bed against the air stream is modelled. The results are compared with the experimental data on a model quartz reactor using charcoal. Experimental data of propagation of the reaction front through the packed bed from the present study and of Groeneveld's charcoal gasifier are used for comparison. Using the analysis of Dosanjh et al. 1987 (Combust. Flame 68: 131-142), it is shown that heat loss dominates the heat generation at the quench condition. It is also shown that increasing the oxygen fraction in air has resulted in flame front to propagate into the char bed. The critical air mass flux for peak propagation rate in a bed of char is found to be $0.1 \mathrm{~kg} \mathrm{~m}^{-2} \mathrm{~s}$. Copyright (C) 2001 John Wiley \& Sons, Ltd.
\end{abstract}

KEY WORDS: gasification; packed bed; char particles

\section{INTRODUCTION}

\subsection{Reactions in packed beds}

The process that occurs in a typical wood gasifier is a heterogeneous reaction in a packed bed with homogeneous heat release in the gas phase. Pyrolysis releases volatiles leaving behind char. Pyrolysis gases undergo exothermic reactions with air to yield products of combustion which further react endothermically with the char leading to the product gas, containing $\mathrm{CO}, \mathrm{CO}_{2}, \mathrm{H}_{2}$, $\mathrm{H}_{2} \mathrm{O}$ and $\mathrm{N}_{2}$. Similar processes occur in a packed bed as seen during a fire spread in permeable materials. A number of workers (Dosanjh et al., 1987; Amundson and Arri, 1978; Ohlemiller et al., 1979; Fatehi and Kaviany, 1994) have examined the propagation rate of a flame front against an

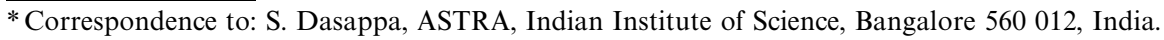


air stream through a packed bed of solids such as char, wood, foam, or biomass. The primary emphasis in these studies has been to predict the flame spread through the media. Only the first process described above, namely, the oxidation, is of importance in predicting the flame spread rate. However, for design and operation of a gasifier, both oxidation and reduction processes are of equal importance.

Torero et al. (1993) have conducted the study on polyurethane foam. In the experimental study they have considered the upward and downward propagation of a smoldering front. They make a parametric study by varying the air flow through the porous bed and obtain temperature profile and smoldering velocity, for both upward and downward configurations. The general trends of profiles of smoldering velocity and temperature are similar for both the cases. There is a gradual increase in the smolder velocity with air velocity, peaking around $0.1-0.15 \mathrm{~mm} / \mathrm{s}$ when the air velocity is $2 \mathrm{~mm} / \mathrm{s}$ for downward propagation and $3 \mathrm{~mm} / \mathrm{s}$ for upward propagation. In the latter case, where air and front movement are in opposite directions, the smoldering velocity decreases with increase in the flow velocity beyond a peak value. Further increase in flow velocity leads to extinction. They argue that the variation of smoldering velocity with air flow rate is due to the excess of heat loss above the heat generation in the region of reducing smoldering velocity. The peak smoldering temperature is found to be about $673-773 \mathrm{~K}$ in both the cases.

Lastrina et al. (1971) have carried out analytical and experimental investigations of the flame spread in a solid fuel bed. The environment considered has $\mathrm{O}_{2}$ along with an inert component. Based on the heat flux into the solid fuel bed, they evolve a criterion which defines the critical thickness separating the behaviour from that of a thick front. They also predict the flame spread velocity at different pressures $(0.007-2.1 \mathrm{MPa})$ and varying ambient $\mathrm{O}_{2}$ concentrations. They obtain a relationship for the spread velocity

$$
V \approx Y_{\mathrm{O}_{2}}^{2.1} P^{0.63}
$$

which they claim is consistent with other data from literature. In the experiments on flame spreading, in convective flow opposed to the flame spread direction, the experimental data exhibit an increase in flame propagation velocity with increase in the flow velocity until a critical value. This result is similar to the one observed by Torero et al. (1993). The data indicate a trend towards reduction in propagation velocity with further increase in the flow velocity. The increasing trend of the data exhibit a correlation $V \propto U^{0.34}$, where $V$ is the propagation velocity and $U$ the gas velocity.

Dosanjh et al. (1987) in their work on the analytic modelling of propagation of a smoldering front through a porous solid fuel, have examined the conditions for a steady smolder front and for the transition to extinction. In their analysis they consider air and fuel moving into the reaction zone, as in the present case. Solving the mass and energy conservation equations by the use of asymptotic analysis, they obtain an expression for the propagation front velocity as

$$
v=\frac{q \dot{m}_{\mathrm{oi}}^{\prime \prime}}{(1-\phi) \rho_{\mathrm{si}} c_{\mathrm{eff}}\left(T_{\mathrm{f}}-T_{\mathrm{i}}\right)}-\frac{\phi \rho_{\mathrm{gi}} u_{\mathrm{i}}}{(1-\phi) \rho_{\mathrm{si}}}
$$

where $q$, the heat release per unit mass of oxygen consumed, $\dot{m}_{\mathrm{oi}}^{\prime \prime}$, the initial oxygen mass flux, $c_{\text {eff }}$, the effective heat capacity, $T_{\mathrm{f}}$ the peak temperature, $T_{\mathrm{i}}$, the initial temperature, $\rho_{\mathrm{gi}}$ and $\rho_{\mathrm{si}}$ the gas and solid density, respectively. 
From the above, they present the relationship between dimensionless smolder velocity $\bar{v}=v / v_{c}$, and the dimensionless temperature $\bar{T}_{\mathrm{f}}=\left(T_{\mathrm{f}}-T_{\mathrm{i}}\right) / T_{\mathrm{i}}$ as

$$
\bar{v}=\frac{1}{T_{\mathrm{f}}}-\frac{1}{D_{\mathrm{c}}}
$$

where $v_{\mathrm{c}}$ is the characteristic velocity due to the balance between the energy released in the reaction zone and the energy required to preheat the solid, $\left[v_{\mathrm{c}}=q \dot{m}_{\mathrm{oi}}^{\prime \prime} /\left((1-\phi) \rho_{\mathrm{si}} c_{\mathrm{eff}} T_{\mathrm{i}}\right)\right]$ and $D_{\mathrm{c}}$ is the dimensionless measure of energy released in the reaction zone relative to the amount of energy required to raise the temperature of gas from $T_{\mathrm{i}}$ to $T_{\mathrm{f}}$.

Using the above analysis they show that the extinction process is related to the heat loss from the reaction front dominating the heat release. They further bring out that for the front to move the minimum oxygen mass fraction in the ambient should be $Y_{\mathrm{oi}}=c_{\mathrm{eff}}\left(T_{\mathrm{f}}-T_{\mathrm{i}}\right) / q$. This indicates the balance between the heat generated at the reaction front and the heat taken away by the incoming gas.

Groeneveld (1980) uses elemental balances for carbon, hydrogen and oxygen and relates different fluxes in the drying, pyrolysis and oxidation zones. In the reduction zone he follows a char particle along the length of the reactor. The heterogeneous reactions of $\mathrm{CO}_{2}$ and $\mathrm{H}_{2} \mathrm{O}$ with char along with the water gas shift reaction are used in the reduction zone. In his analysis, the heterogeneous reaction with $\mathrm{O}_{2}$ is not considered. Bed porosity is taken at 0.5 and the gradients of radial temperature and concentration are assumed to be zero. Radiation, the dominant mode of heat transfer in the bed is modelled as effective heat conductivity. Groeneveld (1980) uses shrinking criterion to define the conversion being completed at a particular location in a given particle, i.e. the amount left over which is unreacted. He varies this factor from 0.1 to about 7 per cent to account for increasing values of shrinking criterion due to which the particle diameter decreases faster and more carbon is entrained with the gas phase. Actually, this choice is to be considered based on the amount of ash content in the fuel chosen. In a numerical experiment, he obtains the conversion as a function of distance in the reduction zone for different particle diameters. Groeneveld (1980) indicates that with small particle diameters the conversion rate is higher due to better heat and mass transfer at the beginning of the reduction zone. Further, with greater conversion the kinetic limit is reached and hence a slightly shorter length of reduction zone is required in the case of small particles. He compares the results of the analysis with those from the experiments. The differences are attributed to the complexities of the processes taking place in the reactor. The solid and gas temperatures are presented along with the experimental results. Comparison of these with those from the char bed reactor shows that the peak temperature is lower by $200 \mathrm{~K}$. Based on the available data it is found that the air flux in the wood gasifier reactor is about six times that of the char reactor. The predicted gas and solid temperatures in the wood gasifier reach a maximum of 1600 and $1400 \mathrm{~K}$ at the reduction zone, respectively. Groeneveld (1980) has not brought out the reason for such a difference. The higher temperature in the wood gasifier is taken as a contribution from the increased mass flux along with the gas-phase combustion of the volatiles released in the pyrolysis zone. As the amount of fuel consumed in this reaction zone (of gaseous fuel combustion) is high, the temperature peaks up. Based on his study, he recommends a reduction volume of $0.5 \mathrm{~m}^{3} / \mathrm{m}^{2}$ of the throat.

In this paper, a packed bed of char particles is considered for analysis. The packed char bed is modelled by extending the single-particle analysis. All the reactions related to gasification are 
introduced into the reaction system. In Dasappa et al. (1998), some experimental results and the initial attempt for packed bed of char is brought out. Further, these have been discussed in Dasappa (1999). The propagation of the reaction front into the packed char bed against the air stream is modelled. The results are compared with the experimental data on a model quartz charcoal reactor. With regard to the propagation of the reaction front through the packed bed, the experiments of Groeneveld on his charcoal gasifier are used for comparison. Using the analysis from Dosanjh et al. (1987), it is shown that heat loss is dominating the heat generation at the quench condition. Increasing oxygen fraction in air has resulted in the propagation for the front.

\section{EXPERIMENTAL SET-UP AND PROCEDURE}

For measuring the propagation rates, experiments similar to those performed by Reed and Markson (1983) are conducted. A quartz reactor of $65 \mathrm{~mm}$ diameter and $400 \mathrm{~mm}$ height, insulated leaving an observation slit of $10 \mathrm{~mm}$ wide throughout the length, is used as shown in Figure 1. This reactor corresponds to a one-fortieth scale version of the state-of-the-art wood gasifier of $275 \mathrm{~kW}$ thermal rating (Mukunda et al., 1994). The other elements used are similar to those in the commercial large gasifiers - a grate to hold the charge and, tubing to draw the gas to the cooler through a blower and into a swirl burner. Dried charcoal pieces, approximately cubical and of $8 \mathrm{~mm}$ size are used as feed. After initial light-up through the ignition port above the grate, the air nozzle is closed to allow the system to draw air from the top. It is observed that the flame front moves upwards, towards the top from where air is being drawn and, eventually the front reaches the top. Experiments are stopped when the flame front reaches the top. The system is run at fixed flow rates and the upward rate of propagation of the flame front is measured. Thermocouples are positioned at different heights as shown in Figure 1, to provide the temperature data. Temperature-time data are acquired on-line by a computer. The exit gas composition is determined using on-line analysers for hydrogen, carbon monoxide, carbon dioxide and oxygen. The temperature profile is further used to obtain the reaction front movement, i.e. propagation front velocity. It is observed that the glowing zone is approximately $25-35 \mathrm{~mm}$ deep (3-4 particle

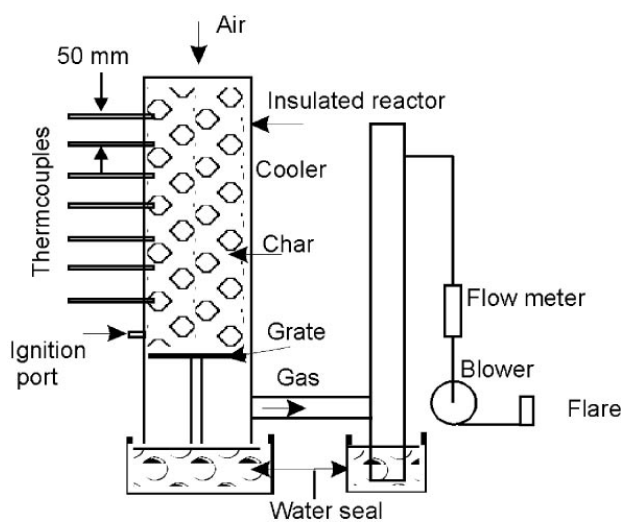

Figure 1. Experimental set-up for the packed-bed reactor. 
Table I. Different parameters measured during the experiments.

\begin{tabular}{lcc}
\hline $\begin{array}{l}\text { Mass flux range } \\
\left(\mathrm{kg} / \mathrm{m}^{2} \mathrm{~s}\right)\end{array}$ & $\begin{array}{c}\text { Bed temperature } \\
(\mathrm{K})\end{array}$ & $\begin{array}{c}\text { Gas composition } \\
\text { (per cent) }\end{array}$ \\
\hline $0.015-0.30$ & 8 locations & $\mathrm{O}_{2}, \mathrm{CO}_{2}, \mathrm{CO}, \mathrm{H}_{2}$ \\
\hline
\end{tabular}

depth) and the peak temperature measured in the bed is in the range of 1000-1230 K depending upon the mass flux. At low mass flux, i.e. below about $0.05 \mathrm{~kg} / \mathrm{m}^{2} \mathrm{~s}$, the gas is not combustible and the $\mathrm{CO}$ level is very low $(<1$ per cent). In most of the cases, measured hydrogen in the gas is about 2.0-4.5 per cent.

Table I gives the different parameters measured during the experiments. About 5-8 experiments have been conducted at each of the mass flow rates in the range mentioned. All the experiments are carried out using a particle size of $8 \mathrm{~mm}$ equivalent diameter. The gas analysers were calibrated using standard gases in the range of the values of each of the gaseous species.

\section{PROPAGATION RATE IN PACKED BEDS}

The temperature profiles at a particular mass flux are shown in Figure 2. Different profiles indicate temperatures at different locations in the reactor as functions of time. Based on this information the rate of movement of the thermal profile or the propagation rate can be obtained. The process of the front moving up is termed as stratification following the literature (Reed and Markson, 1983). The front moving up is similar to the process of flame front moving in a flame speed experiment involving a premixed gas mixture. The front moves into the unburnt zone which is a premixed fuel-air gaseous mixture, while here it is a heterogeneous process involving char and air as the reaction system. The front movement varies with the mass flux. In Figure 2, considering the thermocouples located at $x=100$ and $200 \mathrm{~mm}$, the propagation rate is $0.25 \mathrm{~mm} / \mathrm{s}$ at a flux of $0.06 \mathrm{~kg} / \mathrm{m}^{2} \mathrm{~s}$. The peak temperature in this case is about $1100 \mathrm{~K}$. Table II gives measured values of the flux, peak temperature and the $\mathrm{CO}$ concentration in the gas. It is clear that increase in flux increases the peak temperature and the $\mathrm{CO}$ content in the output gas.

Figure 3 shows the variation of propagation rate of the reaction front in a packed bed of char with the superficial air mass flux through the bed. Experimental results from the present work and from those of Reed and Markson (1983) are also included in the same figure. With increase in mass flux, the front velocity initially increases attaining a peak at a flux of $0.1 \mathrm{~kg} / \mathrm{m}^{2} \mathrm{~s}$ before reducing further. The peak propagation rate corresponds to a superficial air velocity of $0.1 \mathrm{~m} / \mathrm{s}$. The bed temperature measured at this mass flux is about $1200 \mathrm{~K}$. The experimental data from Reed and Markson (1983) are from an experiment where the flaming combustion is completed and the char combustion/gasification is carried on. The data are on a fuel chip size of $10 \mathrm{~mm}$ cube, similar to the present work. With further increase in mass flux the propagation rate becomes negative, implying that the front does not move up, but moves towards the grate and is finally quenched. The peak temperature and the exit CO mole per cent are also plotted. As can be seen, $\mathrm{CO}$ content in the gas is very small at low air mass flux, and both the peak temperature and the $\mathrm{CO}$ content in the exit increase with air mass flux. 


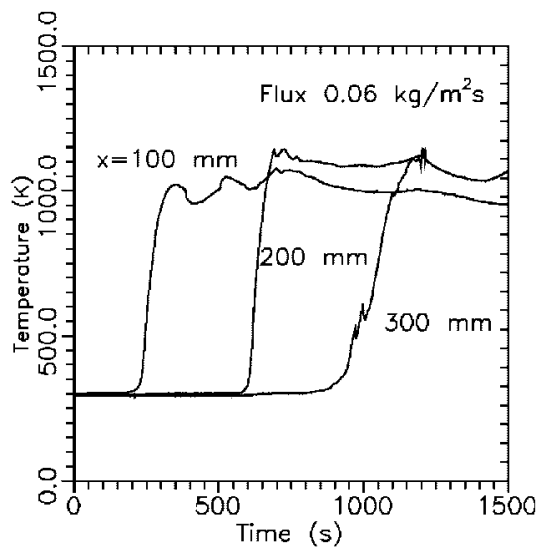

Figure 2. Temperature profiles at different locations (from the bottom of the reactor) in a packed bed at a flux of $0.06 \mathrm{~kg} / \mathrm{m}^{2} \mathrm{~s}$.

Table II. Peak temperature and CO concentration in the gas at varying mass flux in the char bed.

\begin{tabular}{lcc}
\hline $\begin{array}{l}\text { Mass flux } \\
\left(\mathrm{kg} / \mathrm{m}^{2} \mathrm{~s}\right)\end{array}$ & $\begin{array}{c}\text { Peak temperature } \\
(\mathrm{K})\end{array}$ & $\begin{array}{c}\mathrm{CO} \\
\text { (per cent) }\end{array}$ \\
\hline 0.015 & 1000 & 0 \\
0.050 & 1100 & 6.2 \\
0.060 & 1130 & 6.8 \\
0.100 & 1210 & 11.0 \\
0.16 & 1225 & 12.3 \\
0.210 & 1280 & 14.0 \\
0.28 & 1330 & 17.3 \\
\hline
\end{tabular}

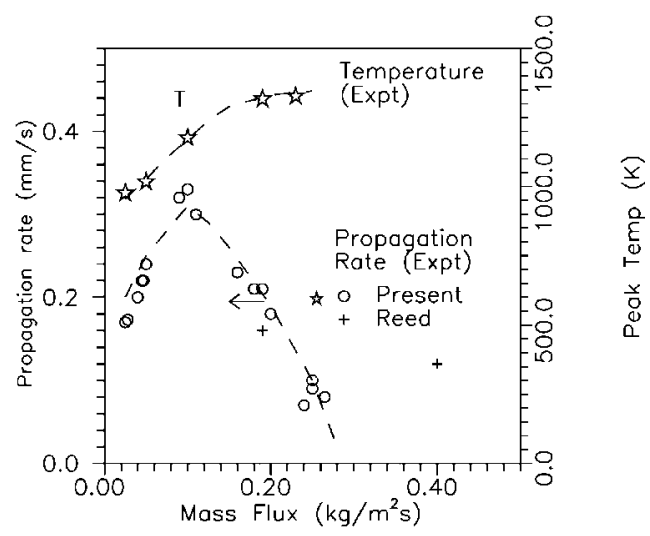

Figure 3. Measured propagation rate and peak temperature in a packed char bed. 


\section{MODELLING OF PARTICLES IN PACKED BEDS}

Gasification is a complex process during which solid fuel reacts with $\mathrm{O}_{2}, \mathrm{CO}_{2}, \mathrm{H}_{2} \mathrm{O}$ and $\mathrm{N}_{2}$ to form a gaseous fuel consisting of $\mathrm{CO}, \mathrm{CO}_{2}, \mathrm{H}_{2}, \mathrm{H}_{2} \mathrm{O}$ and $\mathrm{N}_{2}$. The following are the overall reactions that are likely to take place in the gasification process:

$$
\begin{gathered}
\mathrm{C}+\mathrm{O}_{2} \rightarrow \mathrm{CO}_{2} \\
\mathrm{C}+\mathrm{CO}_{2} \rightarrow 2 \mathrm{CO} \\
\mathrm{C}+\mathrm{H}_{2} \mathrm{O} \rightarrow \mathrm{CO}+\mathrm{H}_{2}
\end{gathered}
$$

The char reactor consists of a packed bed of particles where heterogeneous reactions take place between the reactant and the char. In the present reactor configuration, the particle moves from the top of the reactor where the cold air enters and the products exit at the bottom of the reactor. With increase in the gas flow rate, the fuel consumption also increases. Any change in the gas flow rate results in the change of the rate of movement of the particles in the bed. Thus, in a reactor the particles move with varying speeds, depending upon the gas flow rate. Similarly, with increase in gas flow rate, the mass flux across the reactor also increases, changing the ambient conditions in the vicinity of the particle. This feature has been observed in the experiments conducted as mentioned in the previous section. During the process of its travel inside the reactor, the particle therefore is also exposed to varying environments.

After ignition, the particles react with the incoming air/gaseous species surrounding them to form products of combustion. This reaction is similar to the one described by Dasappa et al. $(1994 a, b)$, where diffusion and convection of the species, energy in the porous medium in the particle and, heterogeneous reaction between the gaseous species and the char are taken into account. The heterogeneous reaction taking place within the particle results in releasing the product gases from the particle. These product gases outside the particle form the gas phase system for the packed bed. The gaseous species surrounding the particle act as the reactants for the heterogeneous reaction.

Thus, in a packed bed, two major processes take place-first, the heterogeneous reactions between the particle and the reacting ambient resulting in the gaseous species. Second, the gas-phase interaction in the bed resulting in the final products of gasification.

In order to analyse the processes occurring in a packed bed, it is necessary to study the reaction taking place inside the particle, heat exchange between the particles, and the gas-phase interaction and are discussed in Dasappa (1999).

\subsection{Gas-phase conservation equations}

Analysis is carried out by setting out the conservation equation for continuity, species and energy in the gas phase. Properties of the bulk fluid surrounding the particles vary continuously as the reaction proceeds. These are determined by solving the set of conservation equations for the bulk gases assuming variations only with the height of the bed. The equations can be written as

$$
\frac{\partial \dot{m}^{\prime \prime}}{\partial x}=n \dot{m}_{\mathrm{p}}
$$




$$
\begin{aligned}
\frac{\partial\left(\varepsilon_{\mathrm{b}} \rho Y_{\mathrm{i}}\right)}{\partial t}+\frac{\partial \dot{m}^{\prime \prime} Y_{\mathrm{i}}}{\partial z}= & \frac{\partial}{\partial x} D \rho \frac{\partial Y_{\mathrm{i}}}{\partial x} \\
& +n\left[\dot{m}_{\mathrm{p}} Y_{\mathrm{i}, \mathrm{s}}+K_{\mathrm{D}}\left(Y_{\mathrm{i}, \mathrm{s}}-Y_{\mathrm{i}}\right)\right]+\dot{w}_{\mathrm{i}}^{\prime \prime \prime} \\
\frac{\partial\left(\varepsilon_{\mathrm{b}} \rho c_{\mathrm{p}} T\right)}{\partial t}+\frac{\partial\left(\dot{m}^{\prime \prime} c_{\mathrm{p}} T\right)}{\partial x}= & \frac{\partial}{\partial x} k_{\mathrm{eff}} \frac{\partial T}{\partial x}+n\left[\dot{m}_{\mathrm{p}} c_{\mathrm{p}} T_{\mathrm{s}}+h A_{\mathrm{s}}\left(T_{\mathrm{s}}-T\right)\right] \\
& +H_{\mathrm{R}}+h_{1} A_{\mathrm{sr}} \Delta T
\end{aligned}
$$

where $n$ is the number of particles per unit volume, $\varepsilon_{\mathrm{b}}$ the bed porosity, $\dot{m}_{\mathrm{p}}$ the gasification rate of one particle $(\mathrm{kg} / \mathrm{s}), \dot{m}^{\prime \prime}$ the superficial mass flux of the gases through the bed $\left(\mathrm{kg} / \mathrm{m}^{2} \mathrm{~s}\right), K_{\mathrm{D}}(\mathrm{kg} / \mathrm{s})$ and $h\left(\mathrm{~kJ} / \mathrm{m}^{2} \mathrm{sK}\right)$ the mass and heat transfer coefficients respectively, through the gas film surrounding the particle (Dasappa et al., 1998). $\dot{w}^{\prime \prime \prime}$ and $H_{\mathrm{R}}$ are the gas-phase reaction rate and the heat generation per unit volume due to gas-phase reactions, respectively. $h_{1}$ is the heat transfer coefficient from the reactor surface to the ambient and $A_{\text {sr }}$ the surface area of the reactor. The subscript $\mathrm{s}$ denotes the properties at the surface of the particle. For calculating $\varepsilon_{\mathrm{b}}$, the internal porosities of particles are not considered; it is considered separately when solving for individual particles. $x$, the distance along the length of the char reactor.

In the char bed reactor under consideration, the superficial air velocity is in the range of $0.1-0.4 \mathrm{~m} / \mathrm{s}$. The change in density occurs mainly when the propagation front crosses a point which is moving at a rate of $0.1-0.3 \mathrm{~mm} / \mathrm{s}$, where the temperature increases from 400 to about $1100 \mathrm{~K}$, in about $30 \mathrm{~mm}$ thick bed. $\Delta \rho / \Delta t$ can be calculated to be equal to approximately $6 \times 10^{-4} \mathrm{~kg} / \mathrm{m}^{3} \mathrm{~s}$. This is indeed very small compared to $n \dot{m}_{\mathrm{p}}$ which is about 1.0 .

The energy conservation equation (Equation (6)) indicates the balance between the unsteady, convective, conductive, heat generation and the heat loss terms. The first term on the left-hand side of the equation represents the unsteady term and the second the convection term. On the right-hand side of the equation, the first term is the conduction term using the effective bed conductivity and the last the heat generation term. These terms form a typical energy conservation equation for a system. The additional term, i.e. the second term on the right-hand side, shows the heat exchange process between the gas and the surrounding particles per unit volume of the bed.

In the conservation Equations (4)-(6), the conditions at the surface of the particles are obtained from the solution of the single-particle analysis. Knowing the surface conditions, the gas-phase system is solved. In comparison with the single-particle analysis, the particle in a packed bed 'views' (interacts with) many other particles surrounding it. Thus, heat exchange between particles has to be considered which is presented in the next section.

\subsection{Heat exchange between particles in a packed bed}

As indicated earlier, heat gains/losses of a particle in the packed-bed reactor are different from that of a single particle in a reacting atmosphere. Figure 4 shows the given particle under study surrounded by others. For handling particle to particle heat transfer, it is assumed that radiation is the major mode of heat exchange (Reed and Markson, 1983; Basak, 1985; Gabor and Bolleril, 1985). Conduction is likely to play only a minor role because the area of contact between particles is small in randomly packed beds and emissivity of char particles is large (close to unity). A particle views the surrounding particles at various heights with different temperatures. 


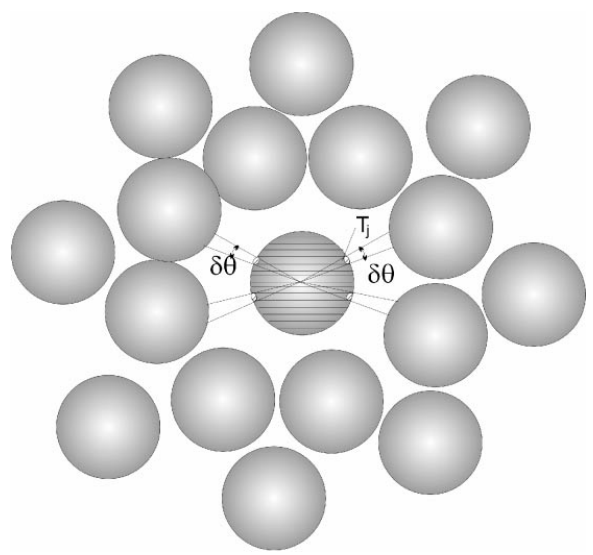

Figure 4. Estimation of radiation exchange between particles.

To account for heat exchange, the surface of the particle is divided into strips of latitudes of width $\delta \theta$ as shown in Figure 4. It is assumed that the view factor of the sphere, with all particles whose centers reside in the latitudinal width $\delta \theta$, is equal to the ratio of the area of the strip to the total surface area of the sphere. All such particles are assumed to have a uniform surface temperature representing the average height at which these particles reside within the bed.

Let $Q_{i}$ be the radiative flux incident on a surface $i$ from other surfaces. Then we get

$$
A_{i} Q_{i}=\sum_{j} A_{j} f_{j i}\left[\varepsilon_{j} \sigma T_{j}^{4}+\left(1-\varepsilon_{j}\right) Q_{j}\right]
$$

From symmetry relation, we have

$$
A_{i} f_{i j}=A_{j} f_{j i}
$$

Substituting into Equation (7), we get

$$
Q_{i}=\sum_{j} f_{i j}\left[\varepsilon_{j} \sigma T_{j}^{4}+\left(1-\varepsilon_{j}\right) Q_{j}\right]
$$

Now, we make a simplifying assumption that all $Q_{j}$ 's are equal. Hence, $Q_{j}$ on the right-hand side can be replaced by $Q_{i}$ and on simplification we obtain

$$
Q_{i}=\frac{\sum_{j} f_{i j} \varepsilon_{j} \sigma T_{j}^{4}}{1-\sum_{j} f_{i j}\left(1-\varepsilon_{j}\right)}
$$

Assuming further that emissivities of all the surfaces are equal, the total radiative flux falling on the sphere and the net radiation absorbed can be obtained as

$$
\begin{aligned}
Q & =\sum_{j} f_{j} \sigma T_{j}^{4} \\
H_{R}^{\prime \prime} & =A_{\mathrm{s}} \alpha\left(Q-\sigma T_{s}^{4}\right)
\end{aligned}
$$


where $A_{\mathrm{s}}$ is the surface area of the sphere and $\alpha$ the absorptivity (or emissivity) of the surface. To calculate $f_{i j}$ the sphere is divided into equal latitudes of magnitude $\delta \theta$ and $f_{i j}$ is obtained as the fraction of the area of the strip to the sphere area. To determine $T_{j}$, the temperature of the latitude section under consideration, it is assumed that the particle views, on an average, other particles at a centre-to-centre distance which is a constant multiple of the particle diametre. This effective distance can be different from the average centre-to-centre distance of the particles in the bed because of the $T^{4}$ relationship for radiation and due to the non-uniformity of the surface temperature of a sphere. In order to estimate this distance, the expression from Gabor and Bolleril (1985), for the radiant heat transport between particle to particle is considered. Gabor and Bolleril (1985) obtained an expression for the radiation exchange between particles in a packed bed as, $k_{\mathrm{r}}^{0}=0.229 \varepsilon \alpha d_{\mathrm{p}} T^{3} \times 10^{-6}$, where $\varepsilon$ is the emmisivity, and $\alpha$, the porosity.

Using the above expression for the estimation of radiation component in a packed bed and the expression for net radiation absorbed on the particle in Equation (12), the effective distance between the particles has been estimated as $0.65 d$, where $d$ is the diameter of the particle. Knowing the distance between the particles, the net radiation component is determined. Based on this, the $T_{j}$ 's at all the latitude locations for the given sphere are determined.

\subsection{Initial and boundary conditions}

The initial condition is the ambient temperature for all the particles in the bed except for some cells near the bottom for which higher temperatures are assigned for ignition. The reactant mass fraction is set in this case as air. In solving for the single particles, the initial conditions as in Dasappa et al. (1994b).

The initial conditions at $t=0$ are the temperature and concentration profiles within the porous char. The temperature is set at the cold ambient condition or at the furnace condition depending on the experimental requirement. The precise nature of the concentration profile does not matter as the transients die down in a small fraction of the conversion time. This is due to the diffusion dependence of the heterogeneous reaction.

The quasi-steady gas-phase conservation equations are

$$
\frac{\dot{m} c_{\mathrm{p}}}{4 \pi r^{2}} \frac{\partial T}{\partial r}=\frac{1}{r^{2}} \frac{\partial}{\partial r}\left(k r^{2} \frac{\partial T}{\partial r}\right)
$$

and

$$
\frac{\dot{m}}{4 \pi r^{2}} \frac{\partial Y_{\mathrm{i}}}{\partial r}=\frac{1}{r^{2}} \frac{\partial}{\partial r}\left(D \rho r^{2} \frac{\partial Y_{\mathrm{i}}}{\partial r}\right)
$$

The solution for the above equations, assuming the Lewis number to be unity, can be written as

$$
\frac{T-T_{\infty}}{T_{\mathrm{s}}-T_{\infty}}=\frac{Y_{\mathrm{i}}-Y_{\mathrm{i} \infty}}{Y_{\mathrm{s}}-Y_{\mathrm{i} \infty}}=\frac{1-\eta}{1-\eta_{\mathrm{s}}}
$$

where $\eta=\exp \left[\left(-\dot{m} c_{\mathrm{p}}\right) /(4 \pi k r)\right]$. The subscript $\mathrm{s}$ refers to the value at the surface of the sphere. Differentiating the above expressions at $r=r_{\mathrm{s}}$ gives the interface conditions as

$$
\left.D_{\mathrm{g}} \rho \frac{\partial Y_{\mathrm{i}}}{\partial r}\right|_{r_{\mathrm{s}}}=Q\left(Y_{\mathrm{i} \infty}-Y_{\mathrm{is}}\right),\left.\quad k \frac{\partial T}{\partial r}\right|_{r_{\mathrm{s}}}=c_{\mathrm{p}} Q\left(T_{\infty}-T_{\mathrm{s}}\right)
$$


where

$$
Q=\frac{\dot{m}}{4 \pi r_{\mathrm{s}}^{2}} \frac{\exp \left(-B_{0}\right)}{\left[1-\exp \left(B_{0}\right)\right]}, \quad B_{0}=\frac{\dot{m} c_{\mathrm{p}}}{4 \pi r_{\mathrm{s}} k}
$$

Equation (17) is obtained from the solution of spherically symmetric one-dimensional conservation equations for the gas phase (Mukunda et al., 1984) and the effect of free and/or forced convection is accounted for by choosing the appropriate value of the Nusselt number. In order to account for the effect of free and forced convection, $B_{0}$ is redefined as

$$
B_{0}=\frac{\dot{m} c_{\mathrm{p}}}{2 \pi r_{\mathrm{s}} k N u}
$$

where $N u$ is the Nusselt number for heat (or mass) transfer on a sphere. In the absence of free or forced convection, $N u=2$, and Equation (18) reduces to Equation (17). In order to account for the effect of radiation also, the equation for temperature gradient is modified to

$$
\left.k \frac{\partial T}{\partial r}\right|_{r_{\mathrm{s}}}=c_{\mathrm{p}} Q\left(T_{\infty}-T_{\mathrm{s}}\right)-\dot{R}^{\prime \prime}
$$

The Nusselt number correlation chosen as in Dasappa (1995), as

$$
N_{R}=0.493 R e^{0.5} ; \quad N_{G}=0.392 \mathrm{Gr}^{0.25} ; \quad N_{K}=N u-2
$$

where $N_{R}$ and $N_{G}$ are related to the Nusselt number through a number of correlations depending upon their relative magnitude (Yuge, 1960).

\subsection{Solution procedure}

The bed is divided into a number of computational cells and conservation equations for a typical particle representing each cell are solved. The solution of equations for packed beds is obtained using a time-split technique. In the first fractional time step, conservation equations for the porous sphere are solved as in Dasappa et al. (1994a). One representative sphere is solved for each computational cell along the height of the bed. Solution of the equations for the particle gives the conditions at the surface of the sphere and the net mass flow from the sphere surface, which are used in the next fractional time step when Equations (4)-(6) are solved. These equations are solved to obtain the variation of properties in the gas phase. Since the co-ordinate system is laboratory fixed the profile moves into the bed.

Knowing the temperature at a particular location in a given cell, the temperatures at other locations are obtained by interpolation. Thus, the temperature distribution within the bed is obtained. For the analysis, the $\delta \theta$ is chosen to be $\phi / 10$ and $\Delta x$ is $5 \mathrm{~mm}$.

Figure 5 shows a typical packed-bed reactor with particles. In the analysis domain, air is drawn in from the top and the gas is drawn out from the bottom. The temperature profile at a mass flux of $0.1 \mathrm{~kg} /\left(\mathrm{m}^{2} \mathrm{~s}\right)$ is shown in Figure 5. Different profiles indicate temperatures at different locations in the reactor. Based on this information the rate of movement of the thermal profile can be obtained. The propagation rate is $0.3 \mathrm{~mm} / \mathrm{s}$. 


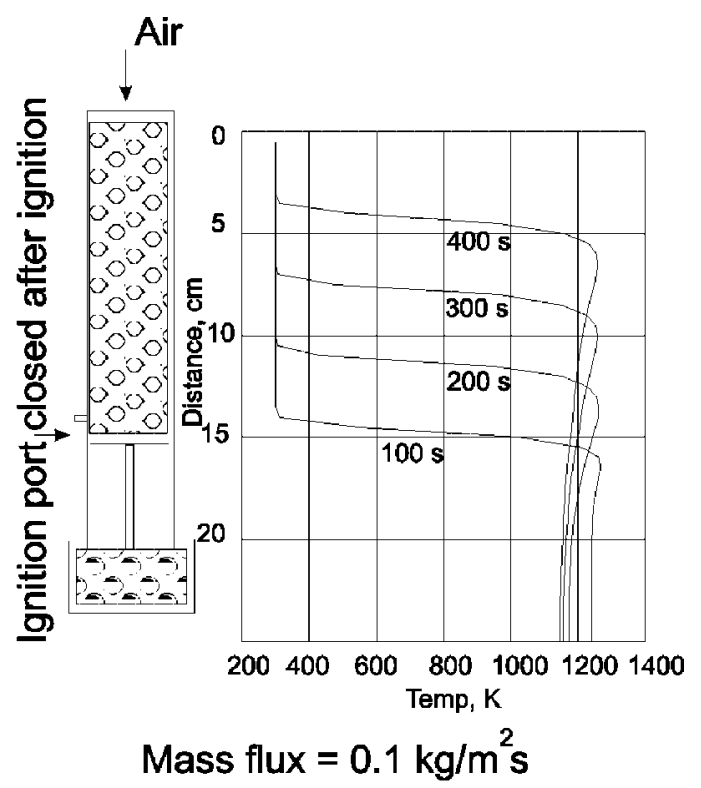

Figure 5. Temperature profile prediction along the length of the reactor.

\section{PROPAGATION RATE IN PACKED BEDS}

Knowing the temperature profile in the bed, the propagation rate for a given mass flow can be determined. Groeneveld (1980) and Mukund et al. (1994) explicitly show that about 8-10 per cent of the input energy in a typical gasifier is lost to the ambient, even though the reactor is insulated. This heat loss from the reactor affects the temperature profile and hence the propagation rate. In order to account for heat lost from the surface in the analysis, the following section addresses the estimation of heat loss.

\subsection{Estimation of heat loss term in the energy Equation (6)}

The energy conservation Equation (3) contains the heat loss term $h_{\ell} A_{\mathrm{sr}} \Delta T$, where $h_{\ell}$ is the heat transfer coefficient, estimated as $10 \mathrm{~W} / \mathrm{m}^{2} \mathrm{~K}$ (Holman, 1989), from the reactor surface and $A_{\mathrm{s}}$ is the reactor surface area.

In simulating the experimental conditions, it was necessary to account for the heat loss from the reactor. Figure 6 shows the gas temperature profiles in the reactor with and without heat loss at the same mass flux $\left(0.1 \mathrm{~kg} / \mathrm{m}^{2} \mathrm{~s}\right)$ at different times. From the profiles, it is clear that the peak temperature in the case of no heat loss from the reactor is about $170 \mathrm{~K}$ higher than the one considering heat loss in the analysis. Also, the propagation rate in the case without heat loss is higher $(0.53 \mathrm{~mm} / \mathrm{s})$ than when heat loss is considered $(0.3 \mathrm{~m} / \mathrm{s})$. The higher value of the propagation rate without heat loss is due to the higher temperature in the bed and higher heat transfer rate between the particles. The prediction of propagation rate with the heat loss term is close to the experimental value of $0.31 \pm 0.05 \mathrm{~mm} / \mathrm{s}$. The predicted peak temperature is in the range of 


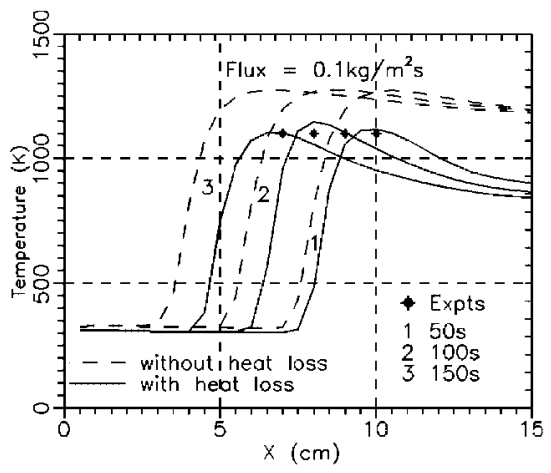

Figure 6. Temperature profile in a packed char bed with and without reactor heat loss (dashed lines - without heat loss, solid lines - with heat loss).

$1100 \mathrm{~K}$, similar to the peak temperature recorded in the experiments. About 7 per cent of the heat value of the fuel has to be considered as heat loss from the reactor. This is consistent with the value of 8 per cent chosen by Groeneveld (1980) for heat loss from the reactor.

5.1.1. Variation of temperature and gas composition in a packed char bed at different fluxes. The profiles of temperature and mole fractions of $\mathrm{CO}$ and $\mathrm{CO}_{2}$ at three different mass fluxes are shown in Figure 7. The profiles are chosen at a time when the rate of propagation of the reaction front through the bed is constant. It can be seen that the peak temperature increases as the air mass flux increases. Measured peak temperature and the peak $\mathrm{CO}$ fraction are also presented in Figure 7 (see Table II). It is also evident that the thickness of the propagation front increases with air flux, which is consistent with the observations during the present experiments. The thickness of the front is the zone where the oxygen is totally consumed. In Figure 7, for increasing flux, the thickness is about 12,40 and $50 \mathrm{~mm}$, respectively. The experimentally observed values at 0.1 and $0.15 \mathrm{~kg} / \mathrm{m}^{2}$ s are about 32 and $40 \mathrm{~mm}$, respectively, amounting to about $4-5$ particles depth. At very low air fluxes, $\mathrm{CO}$ is not generated at any significant level. This feature is also evident during the experiments at low-mass flux when the gas is not combustible at the burner. At larger fluxes, the level of $\mathrm{CO}$ concentration in the exit gas increases. In a char-air system, the equilibrium temperature at which CO begins to form is around $750 \mathrm{~K}$, while the peak is found around $1250 \mathrm{~K}$. Thus, with increasing mass flux, the peak temperature increases favouring more $\mathrm{CO}$ formation.

Figure 8 shows temperature profiles at two different fluxes. Two profiles at different time intervals are presented in each case. From the profiles it is evident that in the first case, with a flux of $0.1 \mathrm{~kg} / \mathrm{m}^{2} \mathrm{~s}$, movement of the front into the bed is evident. For the same time interval, the temperature profile for the case with flux $=0.3 \mathrm{~kg} / \mathrm{m}^{2}$ s shows a tendency for the front to move in the other direction, thus indicating a receding front. In this case the temperature is slightly higher than the one with the $0.1 \mathrm{~kg} / \mathrm{m}^{2} \mathrm{~s}$ case, thus indicating that beyond a particular flux of $0.3 \mathrm{~kg} / \mathrm{m}^{2} \mathrm{~s}$ ), the char reactor ceases to function, due to reverse propagation of the front. Analysis for this behaviour is presented in the following sections.

5.1.2. Variation of propagation front and temperature with mass flux. Figure 9 shows the variation of propagation rate of the reaction front in a packed bed of char with the superficial air mass 


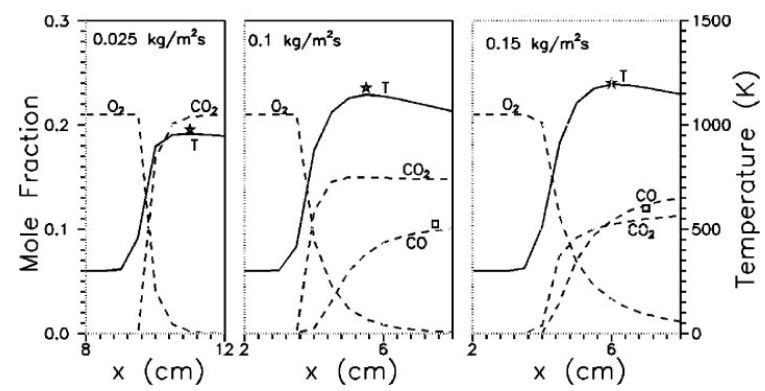

Figure 7. Variation of temperature and the gas composition in a packed char bed at different fluxes along with experimental points.
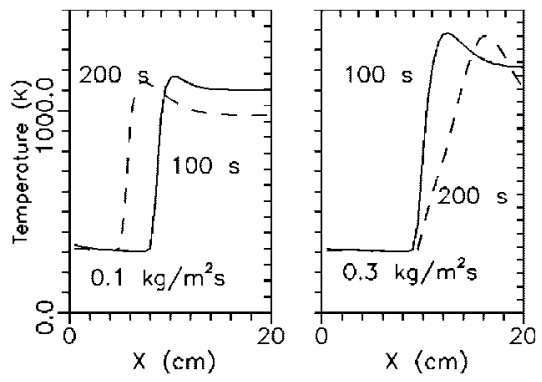

Figure 8. Temperature profiles in the packed char bed at two different fluxes.

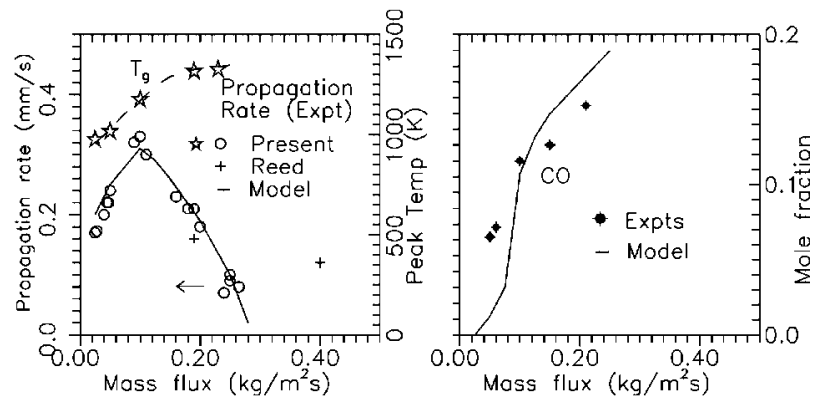

Figure 9. Propagation rate and peak temperature in a packed char bed.

flux through the bed. Experimental results from the present work and from those of Reed and Markson (1983) are also included in the same figure. With increase in mass flux the front velocity initially increases and then reduces.

Similar observations have been made by Torero et al. (1993) and Lastrina et al. (1971) based on experiments with upward propagation using polyurethane foam and fuel beds, where air and propagating front move in opposite directions. Torero et al. (1993) observe trends of initial increase and then decrease of propagation velocity with flow velocity. Figure 10 shows the 


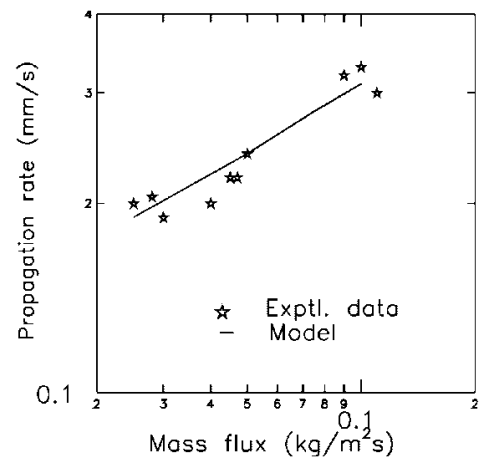

Figure 10. Variation of propagation rate with mass flux in a packed char bed during the increasing regime of propagation rate (experiments_-points, model—solid line).

variation of experimental propagation rate with mass flux, along with the predictions. From Figure 10 it is evident that during the increasing propagation velocity regime, the propagation velocity $(v)$ correlates with the mass flux as $\dot{m}^{\prime \prime(0.36)}$, which is similar to the relation obtained by Lastrina et al. (1971) as $V \propto U^{0.34}$, where $V$ is the propagation velocity and $U$ is the gas velocity.

The peak temperature and the exit $\mathrm{CO}$ mole percent are also plotted in Figure 9. As can be seen, $\mathrm{CO}$ content in the gas is very small at low mass flux, and both the peak temperature and CO content in the exit increase with air mass flux. These results are different from those of Fatehi and Kaviany (1994) who obtain the maximum temperature and maximum front velocity at nearly the same air mass flux. The major difference is that (Fatehi and Kaviany, 1994) use bed material with high volatile content and a major part of this fuel is consumed while the reaction front passes through the fuel. In contrast, in the present case with charcoal, only a small fraction of the fuel is consumed in the reaction front and the situation is fuel-rich in all cases. The reaction front heats up much more fuel than it consumes and this limits the maximum temperature achieved at the flame front. Since the rate of increase of front velocity with air mass flux is less than the rate of increase of air mass flux itself, the peak temperature at the front increases with air mass flux, also aided by the increased heat and mass transfer coefficients between the particle and gas. The front velocity initially increases and then reduces thus indicating the balance of the heat and mass transfer limitations during the process. With further increase in mass flux, as seen in Figure 8, the front moves in the direction of the air flow. This is the case of extinction as indicated by Torero et al. (1993). At these large air mass flux values, the convective cooling of the reactant front reduces the propagation rates even though the temperature of the front keeps increasing.

5.1.3. Analysis of the propagation front movement. Dosanjh et al. (1987), in their work on the analytic modelling of propagation of smoldering front through a porous solid fuel, have examined the conditions for a steady smolder front and for the transition to extinction. In their analysis, they consider the porous bed with air and fuel moving into the reaction zone, as in the present case. Solving the mass and energy conservation equations, they obtain an expression for the propagation front velocity as

$$
v=\frac{q \dot{m}_{\mathrm{oi}}^{\prime \prime}}{(1-\phi) \rho_{\mathrm{si}} c_{\mathrm{eff}}\left(T_{\mathrm{f}}-T_{\mathrm{i}}\right)}-\frac{\phi \rho_{\mathrm{gi}} u_{\mathrm{i}}}{(1-\phi) \rho_{\mathrm{si}}}
$$


where $q$ is the heat release per unit mass of oxygen consumed, $\dot{m}_{\mathrm{oi}}^{\prime \prime}$, the initial oxygen mass flux, $c_{\text {eff }}$, the effective heat capacity, $T_{\mathrm{f}}$ the peak temperature, $T_{\mathrm{i}}$, the initial temperature, and $\rho_{\mathrm{gi}}$ and $\rho_{\mathrm{si}}$ are the gas and solid densities, respectively.

From the above, they present the relationship between the dimensionless smolder velocity $\bar{v}=v / v_{c}$, and the dimensionless temperature $\bar{T}_{\mathrm{f}}=\left(T_{\mathrm{f}}-T_{\mathrm{i}}\right) / T_{\mathrm{i}}$ as

$$
\bar{v}=\frac{1}{T_{\mathrm{f}}}-\frac{1}{D_{\mathrm{c}}}
$$

where $v_{\mathrm{c}}$ is the characteristic velocity due to the balance between the energy released in the reaction zone and that required to preheat the solid, given by $v_{\mathrm{c}}=q \dot{m}_{\mathrm{oi}}^{\prime \prime} /\left((1-\phi) \rho_{\mathrm{si}} c_{\mathrm{eff}} T_{\mathrm{i}}\right)$ and, $D_{\mathrm{c}}$ is the dimensionless measure of the energy released in the reaction zone relative to the amount required to raise the temperature of gas from $T_{\mathrm{i}}$ to $T_{\mathrm{f}}$, defined as $D_{\mathrm{c}}=q Y_{\mathrm{oi}} / c_{\mathrm{eff}} T_{\mathrm{i}}$.

Using the above relationship, the present results are analysed. In carrying out the analysis, $q$, the heat released is calculated based on the heat of combustion for the balanced chemical equation for a particular mass flux. Knowing the gas composition, the chemical equation for a given flux is set out. Based on this balanced chemical equation and, using the heat of combustion of wood char along with the heat of formation of $\mathrm{CO}$ and $\mathrm{CO}_{2}$, the value of $q$ is obtained. Using the results given in Table III, the parameters in Equation (20) are calculated and presented in Table IV.

Table IV gives the values of various quantities using the above analysis. From Table IV, one can see that at lower flux the value of $\bar{v}$ moves from positive values to a negative value. At the point of extinction, the numerical values of $D_{\mathrm{c}}$ and $\bar{T}_{\mathrm{f}}$ are nearly the same. This is the condition at which $v$ will be zero, i.e. all the energy released during the reaction is used to heat the incoming gas; an indication of border line to extinction. The analytical results also predict extinction at a flux of $0.3 \mathrm{~kg} / \mathrm{m}^{2} \mathrm{~s}$ compared with the modelling results discussed earlier. Figure 11 shows the results on the propagation rate with respect to mass flux from the experiments, model and analysis using the work of Dosanjh et al. (1987). At low mass flux, the results from the analysis show that the propagation rate is slightly lower than that of the experimental data, while reasonable agreement exists at mass fluxes of 0.1 and $0.15 \mathrm{~kg} / \mathrm{m}^{2} \mathrm{~s}$. Thus, from the figure it is clear that the results from the analysis and the model are in reasonable agreement with the experimental data.

In Table IV, the critical mass fraction of oxygen necessary for steady front propagation is also presented. The value of $Y_{\mathrm{oi}}=c_{\mathrm{eff}}\left(T_{\mathrm{f}}-T_{\mathrm{i}}\right) / q$, indicates the minimum mass fraction of oxygen required for the front to propagate into the bed suggesting the balance between the energy release at the reaction front and the energy used to heat the incoming gas. The lower the oxygen mass

Table III. Data used in the analysis.

\begin{tabular}{lccc}
\hline $\begin{array}{l}\text { Mass flux } \\
\left(\mathrm{kg} / \mathrm{m}^{2} \mathrm{~s}\right)\end{array}$ & $\begin{array}{c}\text { Temperature } \\
(\mathrm{K})\end{array}$ & $\begin{array}{c}\mathrm{CO} \\
\text { (per cent) }\end{array}$ & $\begin{array}{c}\mathrm{CO}_{2} \\
\text { (per cent) }\end{array}$ \\
\hline 0.05 & 1030 & 5 & 19 \\
0.1 & 1200 & 11 & 14 \\
0.2 & 1300 & 17 & 8 \\
0.3 & 1372 & 25 & 4 \\
\hline
\end{tabular}


Table IV. Values of various quantities from the analysis.

\begin{tabular}{lcccccc}
\hline $\begin{array}{l}\text { Mass flux } \\
\left(\mathrm{kg} / \mathrm{m}^{2} \mathrm{~s}\right)\end{array}$ & $\begin{array}{c}q \\
(\mathrm{~kJ} / \mathrm{kg})\end{array}$ & $D_{\mathrm{c}}$ & $\bar{T}_{\mathrm{f}}$ & $\bar{v}$ & $\begin{array}{c}v \\
(\mathrm{~mm} / \mathrm{s})\end{array}$ & $Y_{\text {oi }}$ \\
\hline 0.05 & 5633 & 3.45 & 2.43 & 0.12 & 0.09 & 0.16 \\
0.1 & 6157 & 3.78 & 2.8 & 0.09 & 0.35 & 0.17 \\
0.2 & 5875 & 3.60 & 3.33 & 0.02 & 0.15 & 0.22 \\
0.3 & 5530 & 3.39 & 3.57 & -0.014 & - & 0.24 \\
\hline
\end{tabular}

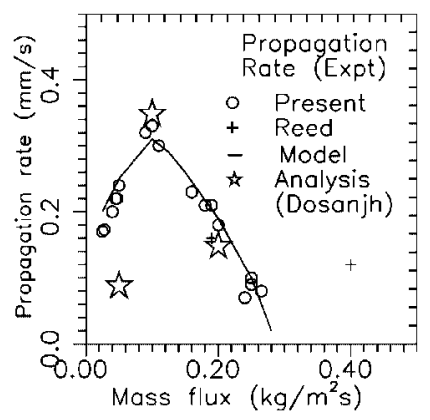

Figure 11. Propagation rate with mass flux in a packed char bed from experiments, model prediction and analysis.

fraction in the ambient, the lower is the heat release in the reaction zone. It is clear that with increase in the mass flux, there is demand for higher mass fraction for the propagation. At $0.3 \mathrm{~kg} / \mathrm{m}^{2} \mathrm{~s}$ the value of $Y_{\mathrm{oi}}$ is 0.24 , i.e. beyond the quantity of air supplied in the present case.

Numerical experiments with an initial oxygen mass fraction of 0.4 in the reactant gas have given exit gas mole fractions for $\mathrm{CO}$ and $\mathrm{CO}_{2}$ as 50 and 1.7 per cent, respectively, at a temperature of $1589 \mathrm{~K}$. Based on these data the value of $\bar{v}$ is 0.133 indicating that the extinction condition is avoided by increasing the oxygen content in the gas. Figure 12 shows the comparison of the temperature profile at $0.3 \mathrm{~kg} / \mathrm{m}^{2} \mathrm{~s}$ mass flux with $Y_{\mathrm{O}_{2}}=0.23$ and 0.4 in the reactant gas. The propagation rate with high oxygen mass fraction in the ambient is $0.53 \mathrm{~mm} / \mathrm{s}$. It is clear that at higher oxygen flux, the propagation front moves into the bed compared with the case of air where it recedes. With increase in oxygen flux, the energy released in the reaction zone exceeds the energy carried by the incoming gas and thus helping the front to move into the bed.

Thus, the model predictions agree well with the present experiments and those of Reed and Markson (1983) in the range of fluxes considered. These details about the front movement with respect to the mass flux could act as a design tool in setting up gasifier/reactor.

Based on the above, one can obtain a turn-down ratio for a given system design to maintain good gas quality. From the data it is clear that the peak front movement is experienced at a mass flux of $0.1 \mathrm{~kg} / \mathrm{m}^{2} \mathrm{~s}$, while a negative movement is found beyond a mass flux of $0.3 \mathrm{~kg} / \mathrm{m}^{2} \mathrm{~s}$. In the range of $0.02-0.1 \mathrm{~kg} / \mathrm{m}^{2} \mathrm{~s}$ there is an increasing trend for the front movement, while a decreasing trend is found from 0.1 to $0.3 \mathrm{~kg} / \mathrm{m}^{2} \mathrm{~s}$. For a steady-state operation it would be advisable to have the mass flux in the range of 0.05 to about $0.15 \mathrm{~kg} / \mathrm{m}^{2} \mathrm{~s}$ to have normal and peak operating 

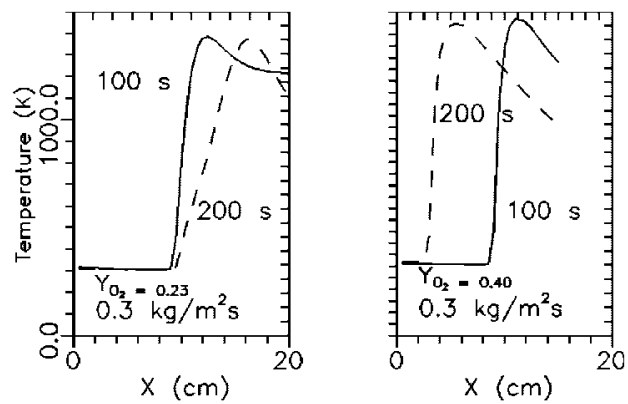

Figure 12. Temperature profiles in a packed bed at different ambient oxygen mass fractions.

conditions. Any further increase in the flux would lead to a blow-off condition. It is to be noted that the effects of other fuel properties like moisture or ash content are yet to be accounted here.

5.1.4. Comparisons with the experiments of Groeneveld. Groeneveld (1980) conducts experiments in a reactor of $0.3 \mathrm{~m}$ diameter with wood char beds made of $25 \mathrm{~mm}$ diameter particles at an air flux of $0.015 \mathrm{~kg} / \mathrm{m}^{2} \mathrm{~s}$. He reports exit CO mole fractions of about 10 per cent and a peak bed temperature of $1180 \mathrm{~K}$. Figure 13 shows the experimental set-up used by Groeneveld (1980) along with results. Temperature and gas compositions are obtained at various locations below the air distributor plate. The results are presented with respect to distance below the air distributor nozzle. The peak temperature in the case of the arrested front is different compared with the propagating flame front case, because of the reasons mentioned earlier. When air is provided through a distributor in the middle of the bed, the front does not propagate beyond this point. Since the front is arrested at a point, the front temperature increases to much higher values compared to the propagating front at the same air flux. This is because the amount of char that needs to be heated is less compared with that of the propagating front.

Figure 14 shows the peak temperature and CO concentration in the gas with varying mass flux, in a packed bed with arrested and propagating fronts. With increase in flux, the peak temperature increases as in the case of the propagating front along with the increase of $\mathrm{CO}$ fraction. It is evident that the peak temperature and $\mathrm{CO}$ concentration for the arrested front are higher than those for the propagating front at the given flux. This feature is evident from Figure 14, where the peak temperature and the $\mathrm{CO}$ mole fraction are presented as functions of the mass flux. From this it is evident that at elevated temperatures the $\mathrm{CO}$ formation in the gasification process cannot be neglected as assumed by Howard (1967).

The results from simulation of these conditions in the model, i.e. the arrested front, are shown in Figure 13. The model predictions on the peak temperature and $\mathrm{CO}$ and $\mathrm{O}_{2}$ mole fractions are consistent with the experiments of Groeneveld, (1980) with some differences in the $\mathrm{CO}_{2}$ mole fraction. The peak temperature is around $1180 \mathrm{~K}$, with a peak CO concentration of 18 per cent. Oxygen is found to deplete in about $35 \mathrm{~mm}$ from the air distributor, i.e. in less than 4 particle depths.

The predictions show reasonable comparison with respect to the experimental results, considering that the processes are complex and the measurement procedures involved. 

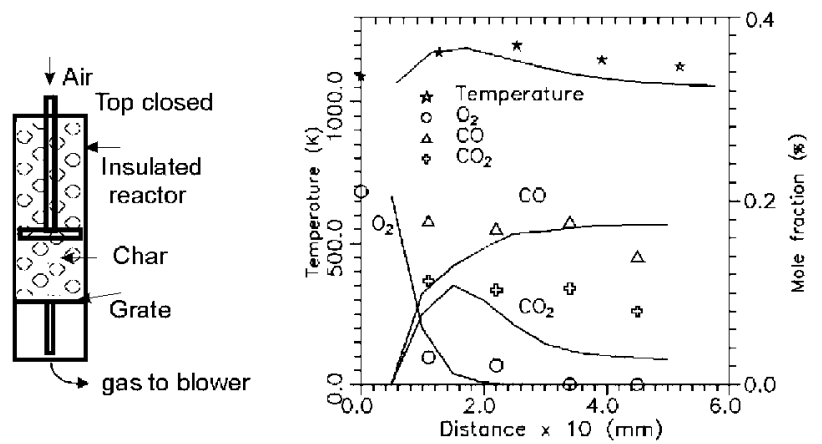

Figure 13. Experimental set-up of Groeneveld with his experimental results and the present predictions at a flux of $0.015 \mathrm{~kg} / \mathrm{m}^{2} \mathrm{~s}$.

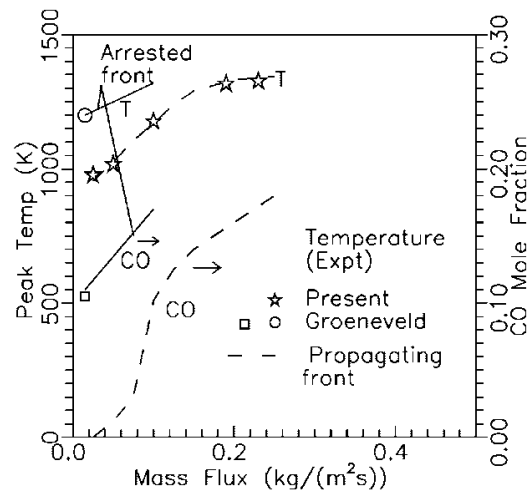

Figure 14. Experimental results of Groeneveld (1980) with arrested front and the present predictions.

5.1.5. Comparisons with equilibrium composition. Table V presents a comparison of the equilibrium compositions at a given temperature along with the data from the model analysis both at a particular flux. Table $\mathrm{V}$ gives the $\mathrm{CO}$ concentration at a particular temperature along with the results from the present work on the propagating front. Comparing the data, the CO concentration at $1465 \mathrm{~K}$ is around 34.3 per cent for equilibrium to prevail, while the predictions show a $\mathrm{CO}$ concentration of 26.6 per cent at the same temperature. From these data, it is clear that there is a departure from chemical equilibrium. The departure from the equilibrium is due to the chemical kinetics involved as well as due to other factors like adiabaticity.

\section{CONCLUSIONS}

The single-particle model is extended to a packed bed of particles. Packed bed analysis is used to determine the propagation front movement, gas and solid temperatures in the bed. The composition of the exit gas is also predicted. The predictions are compared with the present experiments as well with the experimental results of Reed and Markson (1983) and Groeneveld (1980). Peak propagation rate is obtained at a flux of $0.1 \mathrm{~kg} / \mathrm{m}^{2} \mathrm{~s}$, while the peak CO is obtained at higher flux. 
Table V. Comparison with equilibrium calculations.

\begin{tabular}{lcc}
\hline $\begin{array}{l}\text { Temperature } \\
(\mathrm{K})\end{array}$ & $\begin{array}{c}\mathrm{CO} \\
\text { (per cent) }\end{array}$ & Remarks \\
\hline 1465 & 34.2 & $\begin{array}{c}\text { Equilibrium } \\
1465\end{array}$ \\
\hline
\end{tabular}

Beyond a certain flux, i.e. $0.3 \mathrm{~kg} / \mathrm{m}^{2}$ s, propagation ceases and reaches extinction. This feature has been examined using the analysis proposed by Dosanjh et al. (1987). From the analysis it is brought out that extinction occurs when all the energy released in the reaction zone is used in heating the incoming gas. It is also shown from the model that on increasing the heat release in the reaction zone by increasing the oxygen mass fraction in the ambient, the propagation front can be sustained. Thus, a comprehensive model analysis is presented to address several aspects related to packed char bed gasification.

\section{REFERENCES}

Amundson NR, Arri LE. 1978. Char gasification in a countercurrent reactor. A.I.Ch.E. Journal 24(1):87-101.

Basak AK. 1985. Modelling of downdraft charcoal gasifier. Master's Thesis, Asian Institute of Technology, Thailand.

Dasappa S. 1995. Gasification of wood-char spheres in $\mathrm{CO}_{2}-\mathrm{N}_{2}$ mixtures: analysis and experiments. Master's Thesis, Indian Institute of Science, India.

Dasappa S. 1999. Experiments and modelling studies on the gasification of wood-char. Ph.D. Thesis, Indian Institute of Science, India.

Dasappa S, Paul PJ, Mukunda HS, Shrinivasa U. 1994a. The gasification of wood-char spheres in $\mathrm{CO}_{2}-\mathrm{N}_{2}$ mixturesanalysis and experiments, Chemical Engineering Science 49(2):223-232.

Dasappa S, Paul PJ, Mukunda HS, Shrinivasa U. 1998. Wood-char gasification: experiments and analysis on single particles and packed beds. In Twenty-seventh Symposium (International) on Combustion. The Combustion Institute, Pittsburgh, 1335-1342.

Dasappa S, Sridhar HV, Paul PJ, Mukunda HS, Shrinivasa U. 1994b. On the combustion of wood-char spheres in $\mathrm{O}_{2} / \mathrm{N}_{2}$ mixtures - experiments and analysis. In Twenty-Fifth Symposium (International) on Combustion. The Combustion Institute, Pittsburgh, 1619-1628.

Dosanjh SS, Pagni PJ, Fernandez-Pello C. 1987. Forced co-current smoldering combustion. Combustion and Flame 68:131-142.

Fatehi M, Kaviany M. 1994. Adiabatic reverse combustion in a packed bed. Combustion and Flame 99:1-17.

Gabor J, Bolleril J. 1985. Hand Book of Heat Transfer Applications. McGraw-Hill Book Company, New York.

Groeneveld MJ. 1980. The co-current moving bed gasifier. Ph.D. Thesis, Twente University of Technology, Netherlands.

Holman JB. 1989. Heat Transfer. McGraw-Hill Book Company: Singapore.

Howard JB. 1967. Combustion of carbon with oxygen. Technical Report, MIT.

Lastrina FA, Magee RS, McAlevy RF. 1971. Flame spread over fuel beds: solid-phase energy considerations. In Thirteenth Symposium (International) on Combustion. The Combustion Institute, Pennsylvania, 935-948.

Mukunda HS, Paul PJ, Dasappa S, Shrinivasa U, Sharan H, Buehler R, Hasler P, Kaufmann H. 1994. Results of an Indo-Swiss programme for qualification and testing of $300 \mathrm{~kW}$ IISc-Dasag gasifier. Energy for Sustainable Development, the Journal of the International Energy Initiative 1(4):46-50.

Mukunda HS, Paul PJ, Srinivas U, Rajan NKS. 1984. Combustion of wooden spheres - experiments and model analysis. In Twentieth Symposium (International) on Combustion. The Combustion Institute, Pittsburgh, 1619-1628.

Ohlemiller TJ, Bellan J, Rogers F. 1979. A model of smoldering combustion applied to flexible polyurethane foams. Combustion and Flame 36:197-215.

Reed TB, Markson M. 1983. A predictive model for stratified downdraft gasification of biomass. In Proceedings of the Fifteenth Biomass Thermochemical Conversion Contractors Meeting, Atlanta, GA, 217-254.

Torero JL, Fernandex-Pello AC, Kitano M. 1993. Opposed forced flow smoldering of polyurethane foam. Combustion Science and Technology 91:95-117.

Yuge T. 1960. Experiments on heat transfer from spheres including combined natural and forced convection. Journal of Heat Transfer C 82:214-218. 